\title{
Hydrocortisone Sodium Succinate/Aluminum Phosphate Gel
}

National Cancer Institute

\section{Source}

National Cancer Institute. Hydrocortisone Sodium Succinate/Aluminum Phosphate Gel.

NCl Thesaurus. Code C150398.

A gel composed of the sodium succinate form of the glucocorticoid hydrocortisone mixed with aluminum phosphate, with potential protective activity. Upon oral administration of the hydrocortisone sodium succinate/aluminum phosphate gel, the gel forms a layer over the esophageal mucosa, which may restore and protect the esophageal membrane against damage. Hydrocortisone exerts anti-inflammatory effects locally, may reduce or prevent infection, may reduce the formation of connective tissue in order to prevent postoperative esophageal stenosis and stricture, and may reduce symptoms of dysphagia or choking, after endoscopic submucosal dissection (ESD). The aluminum phosphate acts as a buffer and may protect the local mucosal membrane from the acidic environment. 